\title{
ESTUDIO DE LAS POBLACIONES MICROBIANAS DE LA RIZÓSFERA DEL CULTIVO DE PAPA (Solanum tuberosum) EN ZONAS ALTOANDINAS
}

\section{A STUDY OF POTATO (Solanum tuberosum) CROP RHIZOSPHERE MICROBIAL POPULATION IN HIGHLAND ZONES}

\author{
Pamela Calvo Vélez ${ }^{1}$, Luis Reymundo Meneses $^{2}$ y Doris Zúñiga Dávila ${ }^{3}$
}

\begin{abstract}
Resumen
Se evaluaron las poblaciones de microorganismos en la rizósfera del cultivo de papa en dos diferentes regiones Altoandinas. Se encontró que la población de bacterias totales en la rizósfera de las regiones muestreadas siempre fue mayor que la población de hongos; Puno registra mayores poblaciones de bacterias totales, lo que se puede deber entre otros factores al $\mathrm{pH}$ del suelo que es más alcalino que en Huancavelica. Se observa que las poblaciones de Actinomicetos y Azotobacter spp. están influenciadas por el pH y por el tipo de fertilización inorgánica. Asimismo las poblaciones de Bacillus spp. son más abundantes en la región de $\mathrm{pH}$ neutro, sin embargo, su presencia en la región de pH ácido confirma su adaptación a estas condiciones. Se observa también un efecto de la variedad de papa sobre las poblaciones de estos microorganismos en la rizósfera, lo que confirma la influencia de los exudados de la planta sobre las poblaciones rizosféricas. Del total de 17 muestras procesadas se obtuvieron 63 aislamientos de Bacillus spp., 29 (46\%) de Huancavelica y 34 (54\%) de Puno; 37 aislamientos de Actinomicetos, 32 (87\%) de Huancavelica y 5 (13\%) de Puno y 50 aislamientos de Azotobacter spp., 37 (74\%) de Huancavelica y 13 (26\%) de Puno, observándose para estos dos últimos casos una mayor diversidad en suelos de $\mathrm{pH}$ ácido.
\end{abstract}

Palabras clave: Rizósfera, Cultivo de papa, Azotobacter spp., Bacillus spp., Actinomicetos

\begin{abstract}
A study was conducted to investigate the microbial populations of the most representative genera in the potato rhizosphere in Highland regions. Total bacteria population in the two sampling regions was always higher than the fungi population. The more alkaline soil $\mathrm{pH}$ in Puno region can explain this fact. We observed that Actinomycetes and Azotobacter spp. populations were influenced by $\mathrm{pH}$ and type of inorganic fertilization. Also the populations of Bacillus spp. were higher in the region with neutral $\mathrm{pH}$; nevertheless its presence in acid $\mathrm{pH}$ zones confirms its adaptation to these conditions. A potato variety effect was also observed on the microbial rhizospheric population which confirms the influence of plant exudates on the rhizosphere. From the total 17 rhizosphere samples processed, we isolated 63 Bacillus spp. 29 (46\%) of Huancavelica and 34 (54\%) of Puno; 37 Actinomycetes, 32 (87\%) of Huancavelica and 5 (13\%) of Puno and 50 of Azotobacter spp. 37 (74\%) of Huancavelica and 13 (26\%) of Puno; in these two last cases a higher diversity was found in the rhizosphere of the region with acidic $\mathrm{pH}$.
\end{abstract}

Key words: Rhizosphere, Potato Crop, Azotobacter spp., Bacillus spp., Actinomycetes

\section{Introducción}

La papa es el cuarto principal producto alimenticio en el mundo, después del trigo, el arroz y el maíz; Perú ocupa el lugar número 23 entre los principales países productores de papa, participando con $0.7 \%$ de la producción mundial, estimada en 290 millones de toneladas al año (promedio del periodo 1990-2000) (MINAG, 2003), por lo tanto constituye un cultivo de gran importancia, incidiendo en la economía local de un alto número de localidades involucradas en el cultivo del mismo y siendo la base de la alimentación de la población altoandina. Dichas localidades están distribuidas desde el nivel del mar hasta elevaciones superiores a los $3900 \mathrm{msnm}$. Este cultivo se enfrenta a muchos problemas, entre ellos está el continuo deterioro de los suelos, lo cuál afecta a la microbiota del suelo, por lo tanto el estudio de la relación microorganismo-planta es muy importante ya que permite establecer una relación entre el tipo de suelo, la variedad de planta y la microbiota asociada. Todos los microorganismos cumplen un rol fundamental en el mantenimiento del suelo como ecosistema (Loynachan, 2001; Paul \& Clark, 1989). Entre los microorganismos habitantes del suelo las bacterias, incluidos los Actinomicetos, son los más abundantes pues se les encuentra presentes en un rango aproximado de $10^{6}$ y $10^{8}$ células por gramo de suelo pesando aproximadamente $10000 \mathrm{~kg} / \mathrm{ha}$, que representa el $5 \%$ del total de material orgánica seca presente en el suelo. En cuanto a los hongos, dado su 
mayor tamaño aunque menor abundancia, tienen la biomasa más significativa (Alexander, 1994; Tate, 1995), representando un 10 a $20 \%$ de la microbiota total, esto es aproximadamente $10^{5}$ a $10^{6}$ organismos / gramo de suelo.

Es importante mencionar que existen varios factores abióticos que influencian la vida de los microorganismos en el suelo. Uno de los factores más importantes es el $\mathrm{pH}$. Una modificación de éste puede activar o casi inactivar las enzimas de los microorganismos; el $\mathrm{pH}$ también actúa sobre la disponibilidad o fijación de minerales nutritivos. Se puede decir que, en suelos con $\mathrm{pH}$ de 5.6 la mayoría de los microorganismos beneficiosos para los cultivos existen, y sus enzimas son activas. Las bacterias necesitan de nutrientes como los de los exudados de las plantas, porque ante la ausencia de éstos no son capaces de utilizar la materia orgánica como fuente de energía, siendo ésta utilizada solo por hongos. Por esta razón es importante también la aplicación de nutrientes que sean indispensables para el desarrollo de los microorganismos.

La abundancia de bacterias en la rizósfera en comparación con otros microorganismos se puede deber a su rápido crecimiento y la habilidad que presentan de utilizar un amplio rango de sustratos como fuentes de carbono o nitrógeno (Glick, 1995). La cantidad de bacterias que se van a encontrar depende de muchos factores como son: la temporada, el tipo de suelo, la vegetación, el contenido de humedad, el tipo de labranza y fertilización (Killian et al., 2001). Si hablamos del hábitat específico de las bacterias, algunas se pueden encontrar adheridas a la superficie de las partículas de suelo como agregados o interactuando específicamente con las raíces de las plantas; sin embargo, la concentración de bacterias por gramo de suelo que se halla alrededor de las raíces de las plantas en la llamada rizósfera es mucho mayor que en el resto del suelo (Lynch, 1990). Esto se puede deber a los altos niveles de nutrientes que se hallan en la zona que rodea a las raíces y que permiten el desarrollo de poblaciones microbianas (Glick, 1995). La rizósfera ha sido definida por Hiltner (1904), como el volumen de suelo influenciado por la presencia de raíces de una planta viva, cuya extensión puede variar de acuerdo al tipo de suelo, la especie de planta, su edad y otros factores (Foster, 1998). Se sabe que en la rizósfera la interacción entre las bacterias y las raíces de las plantas puede ser beneficiosa, en este caso se puede considerar la rizósfera como una zona de amortiguación microbiológica en donde la microbiota sirve de protección a la planta frente al ataque de patógenos (Krupa \& Dommergues, 1981). Se estima que los exudados rizosféricos pueden llegar a contener entre 10 y $44 \%$ del carbono asimilado y otra serie de compuestos, lo que contribuye generalmente a un incremento de las densidades poblacionales de los microorganismos (Primavesi, 1984).

Dada su abundancia, el componente microbiano del suelo es importante para la salud de los ecosistemas. Los procesos agrícolas, así como el manejo de los recursos vegetales inciden sobre este componente afectando tanto a su biodiversidad como a la densidad de las poblaciones microbianas implicadas; los resultados a mediano y largo plazo pueden ser la pérdida de fertilidad de los suelos y su progresiva depauperación (Olalde \& Aguilera, 1998).

Por todo ello, este trabajo tiene por objeto estudiar la microflora de la rizósfera del cultivo de papa en zonas altoandinas.

\section{Materiales y Métodos}

Lugar de muestreo de rizósfera del cultivo de papa y toma de muestras

En la presente investigación se trabajó con muestras de rizósferas de cultivo de papa de dos regiones. La primera corresponde a la localidad de San José de Aymara en Huancavelica y la segunda se ubica en el departamento de Puno. Estas dos regiones se caracterizan por ser representativas productoras de papa a la vez que mantienen condiciones de suelo, clima altura y características de campo diferentes (Tablas 1, 2 y 3). De la región Huancavelica se muestrearon dos campos de cultivo. En el campo 1 el tipo de fertilización usada fue una mezcla de orgánica y química (N-P-K) y hubo presencia de dos variedades: Peruanita y Amarilla Tumbay (variedades nativas); de este campo se tomaron dos muestras (muestra 1 y 2 de la Tabla 1). El campo 2 se caracterizó por presentar diferentes tratamientos con fertilización orgánica y química; en este caso, el campo sólo presentaba una variedad sembrada que era la Peruanita; de este campo se obtuvieron un total de 6 muestras (muestras 3 a 8 de la Tabla 1). En la región correspondiente a Puno se muestrearon un total de nueve campos ubicados en diferentes localidades alrededor del Lago Titicaca, obteniéndose un total de nueve muestras (muestras 9 a 17 de la Tabla 1). Las muestras de rizósfera fueron tomadas en la época cercana a la cosecha y cada muestra se analizó por duplicado. Se muestrearon las rizósferas (raíces y el suelo que rodea la planta) de 4 plantas al azar ubicadas en cada uno de los campos realizando un mezcla. De las 4 plantas se obtuvo una cantidad aproximada de 1 kg de muestra; estas se colocaron en bolsas de plástico de primer uso rotuladas y posteriormente se transportaron en un "cooler" al laboratorio para los análisis respectivos.

Determinaciones de la microflora de la rizósfera del cultivo de papa

Se pesaron 10 gr de suelo de cada rizósfera (capa de suelo adherida a las raíces), se colocaron en una botella de vidrio estéril con $90 \mathrm{ml}$ de agua peptonada al $0.1 \%$ agitándose 25 veces de manera vigorosa 
Tabla 1. Características de las regiones de muestreo de suelo rizosférico de papa

\begin{tabular}{|c|c|c|c|c|c|c|}
\hline Muestra & Ubicación & $\begin{array}{c}\text { Temperatura } \\
\left({ }^{\circ} \mathrm{C}\right)\end{array}$ & Altura & Precipitación & Tipo de fertilización & $\begin{array}{l}\text { Variedad } \\
\text { de papa }\end{array}$ \\
\hline 1 & $\begin{array}{l}\text { Huancavelica } \\
\text { Aymara }\end{array}$ & $8-9$ & 4200 & $700 \mathrm{~mm}$ & 3.9t guano + 83N-48P-116K/ha & Peruanita \\
\hline 2 & $\begin{array}{l}\text { Huancavelica } \\
\text { Aymara }\end{array}$ & $8-9$ & 4200 & $700 \mathrm{~mm}$ & $3.9 t$ guano $+83 \mathrm{~N}-48 \mathrm{P}-116 \mathrm{~K} / \mathrm{ha}$ & Amarilla \\
\hline 3 & $\begin{array}{l}\text { Huancavelica } \\
\text { Aymara }\end{array}$ & 8-9 & 4030 & $600 \mathrm{~mm}$ & Control (5t guano de corral/ha) & Peruanita \\
\hline 4 & $\begin{array}{l}\text { Huancavelica } \\
\text { Aymara }\end{array}$ & $8-9$ & 4030 & $600 \mathrm{~mm}$ & Nitrato (120 N/ha) & Peruanita \\
\hline 5 & $\begin{array}{l}\text { Huancavelica } \\
\text { Aymara }\end{array}$ & $8-9$ & 4030 & $600 \mathrm{~mm}$ & $\begin{array}{c}\text { Cal + nitrato } \\
\text { ( Dosis } 60 \mathrm{~N} / \text { ha y } 5 \text { t/ha de cal ) }\end{array}$ & Peruanita \\
\hline 6 & $\begin{array}{l}\text { Huancavelica } \\
\text { Aymara }\end{array}$ & 8-9 & 4030 & $600 \mathrm{~mm}$ & Fosfato (100 P/ha) & Peruanita \\
\hline 7 & $\begin{array}{l}\text { Huancavelica } \\
\text { Aymara }\end{array}$ & $8-9$ & 4030 & $600 \mathrm{~mm}$ & $\begin{array}{c}\text { Guano + nitrato } \\
\text { (60 N/ha y } 5 \text { t/ha de guano de corral) }\end{array}$ & Peruanita \\
\hline 8 & $\begin{array}{l}\text { Huancavelica } \\
\text { Aymara }\end{array}$ & 8-9 & 4030 & $6000 \mathrm{~mm}$ & $\begin{array}{c}\text { Nitrato+ fosfato } \\
(120 \mathrm{~N} / \mathrm{ha} \mathrm{y} 100 \mathrm{P} / \mathrm{ha})\end{array}$ & Peruanita \\
\hline 9 & $\begin{array}{l}\text { Puno } \\
\text { Ichu }\end{array}$ & 10 & $3900-4000$ & $700 \mathrm{~mm}$ & 3.1t guano $+73 \mathrm{~N}-30 \mathrm{P}-71 \mathrm{~K} / \mathrm{ha}$ & Ccompis \\
\hline 10 & $\begin{array}{c}\text { Puno } \\
\text { Oquesilla }\end{array}$ & 10 & $3900-4000$ & $700 \mathrm{~mm}$ & 3.1t guano + 73N-30P-71K/ha & Ccompis \\
\hline 11 & $\begin{array}{c}\text { Puno } \\
\text { Tinicachi }\end{array}$ & 10 & $3900-4000$ & $700 \mathrm{~mm}$ & 3.1t guano $+73 \mathrm{~N}-30 \mathrm{P}-71 \mathrm{~K} / \mathrm{ha}$ & Ccompis \\
\hline 12 & $\begin{array}{l}\text { Puno } \\
\text { Thunco }\end{array}$ & 10 & $3900-4000$ & $700 \mathrm{~mm}$ & 3.1t guano $+73 \mathrm{~N}-30 \mathrm{P}-71 \mathrm{~K} / \mathrm{ha}$ & Ccompis \\
\hline 13 & $\begin{array}{l}\text { Puno } \\
\text { Challa }\end{array}$ & 10 & $3900-4000$ & $700 \mathrm{~mm}$ & 3.1t guano $+73 \mathrm{~N}-30 \mathrm{P}-71 \mathrm{~K} / \mathrm{ha}$ & Ccompis \\
\hline 14 & $\begin{array}{l}\text { Puno } \\
\text { Chilacollo }\end{array}$ & 10 & $3900-4000$ & $700 \mathrm{~mm}$ & 3.1t guano $+73 \mathrm{~N}-30 \mathrm{P}-71 \mathrm{~K} / \mathrm{ha}$ & $\begin{array}{l}\text { Imilla } \\
\text { Negra }\end{array}$ \\
\hline 15 & $\begin{array}{l}\text { Puno } \\
\text { Anccaca }\end{array}$ & 10 & $3900-4000$ & $700 \mathrm{~mm}$ & 3.1t guano $+73 \mathrm{~N}-30 \mathrm{P}-71 \mathrm{~K} / \mathrm{ha}$ & Ccompis \\
\hline 16 & $\begin{array}{l}\text { Puno } \\
\text { Cuturapi }\end{array}$ & 10 & $3900-4000$ & $700 \mathrm{~mm}$ & 3.1t guano + 73N-30P-71K/ha & $\begin{array}{l}\text { Imilla } \\
\text { Negra }\end{array}$ \\
\hline 17 & $\begin{array}{l}\text { Puno } \\
\text { Ticuyo }\end{array}$ & 10 & $3900-4000$ & $700 \mathrm{~mm}$ & 3.1t guano $+73 \mathrm{~N}-30 \mathrm{P}-71 \mathrm{~K} / \mathrm{ha}$ & $\begin{array}{l}\text { Imilla } \\
\text { Negra }\end{array}$ \\
\hline
\end{tabular}

(dilución $10^{-1}$ ) y se llevaron a cabo diluciones decimales seriadas en agua peptonada. Se cuantificaron poblaciones de Azotobacter spp. según, Zapater (1975) y Zúñiga \& Gutiérrez-Correa (1982), utilizándose 3 tubos por dilución que contenían medio mineral sin nitrógeno con indicador azul de bromotimol a $\mathrm{pH} 7 \mathrm{y}$ se incubaron a $28^{\circ} \mathrm{C}$ por 7 días. La presencia o ausencia del velo superficial característico, la turbidez y el cambio de color del indicador dan resultados positivos o negativos en cada tubo, estos datos fueron transformados para su expresión en número más probable por gramo de suelo rizosférico seco (NMP/grs). Para el recuento de bacterias totales, se utilizó el medio de cultivo Plate Count Agar (PCA) donde se incubaron las placas durante 48 horas a $28^{\circ} \mathrm{C}$ (APHA-AWWA, 1998). Para hongos totales se utilizó el medio de cultivo Potato Dextrose Agar (PDA) y la incubación se realizo durante 6 días a $25^{\circ} \mathrm{C}$. Para el recuento de Actinomicetos se utilizó el medio almidón-caseína adicionándole fluconazol al $0.25 \%$ para inhibir el crecimiento de hongos y las placas se incubaron a $28^{\circ} \mathrm{C}$ por un período total de 10 días (APHA AWWA, 1998). Por último la cuantificación de colonias de Bacillus se realizó en medio Triptona Glucosa Extracto de Levadura (TGE) incubando las placas a $28^{\circ} \mathrm{C}$ durante 48 horas (APHA -AWWA, 1975; Merck, 1994). Todos los resultados se expresaron en ufc/gr de suelo rizosférico seco.

Aislamientos de bacterias

A partir de las placas de aislamiento se picaron las colonias típicas de Bacillus spp. y Actinomicetos en placas nuevas hasta obtener colonias puras. Para el aislamiento de Bacillus, con la finalidad de obtener cultivos más puros, también se realizó un pretratamiento de la primera dilución de la muestra de suelo rizósférico por calentamiento a $80^{\circ} \mathrm{C}$ en baño maría durante 30 minutos. A partir de esta dilución se prosiguió con las siguientes diluciones y se plaqueó en medio TGE por incorporación (Foldes et al., 2000). En el caso de Azotobacter spp., se tomo una alícuota de los tubos positivos y se sembró por estría en placas con medio mineral sin nitrógeno con indicador púrpura de bromocresol (Zúñiga \& Gutiérrez-Correa, 1982); las placas se incubaron a $28^{\circ} \mathrm{C}$ durante 5 días. Se confirmaron los diferentes tipos de las bacterias mediante tinción Gram y observación al microscopio.

\section{Resultados y Discusión}

El análisis de las poblaciones microbianas presentes en la rizósfera puede reflejar las condiciones del cultivo y la diversidad microbiana encontrada 
refleja la salud de un ecosistema (Ariena et al., 2006). Los resultados de bacterias totales, hongos totales, Actinomicetos, Azotobacter spp. y Bacillus spp. se observan en las Tablas 3, 4 y 5. Las características fisicoquímicas de las dos regiones muestreadas (Tabla 2) indican que la región de Puno se caracteriza por poseer suelos Franco-arenosos mientras que los campos de la región de Huancavelica son Francos. Los valores de $\mathrm{pH}$ en promedio para los campos de Puno son mayores que los encontrados en Huancavelica. En cuanto al contenido de materia orgánica y otros nutrientes según el Ministerio de Agricultura y Alimentación (1978), la materia orgánica en los suelos de Puno presenta valores medios mientras que los de Huancavelica son valores considerados como altos; el contenido de potasio en el suelo de Puno se considera como medio mientras que para Huancavelica es bajo y en el caso del fósforo su presencia es alta en Puno y media en Huancavelica.

Tabla 2. Características fisicoquímicas de los suelos de las dos regiones muestreadas.

\begin{tabular}{|c|c|c|}
\hline & Puno & Huancavelica \\
\hline $\mathrm{Ph}$ (promedios) & $6.25+/-0.13$ & $5.8+/-0.28$ \\
\hline C.E dS/m & 0.46 & 0.58 \\
\hline $\mathrm{CaCO}_{3}(\%)$ & 0 & 0.00 \\
\hline M. O (\%) & 2.64 & 6.60 \\
\hline $\mathrm{P}(\mathrm{ppm})$ & 20.195 & 8.40 \\
\hline $\mathrm{K}(\mathrm{ppm})$ & 231.04 & 75.00 \\
\hline Arena (\%) & 63.96 & 51.00 \\
\hline Limo (\%) & 27.04 & 41.00 \\
\hline Arcilla (\%) & 9 & 8.00 \\
\hline Clase Textural & Franco arenoso & Franco \\
\hline CIC* (me/100g) & 10.695 & 19.85 \\
\hline $\mathrm{Ca}^{2}$ (me/100g) & 2.93 & 6.56 \\
\hline $\mathrm{Mg}^{2}$ (me/100g) & 0.635 & 0.84 \\
\hline K (me/100g) & 0.34 & 0.10 \\
\hline $\mathrm{Na}(\mathrm{me} / 100 \mathrm{~g})$ & 0.08 & 0.22 \\
\hline $\mathrm{AI}^{3}+\mathrm{H}(\mathrm{me} / 100 \mathrm{~g})$ & 0.78 & 0.38 \\
\hline
\end{tabular}

* Capacidad de intercambio catiónico

El comportamiento general de la rizósfera para las dos regiones registra siempre una mayor población de bacterias totales que estuvieron entre $10^{6}$ y $10^{8} \mathrm{ufc} / \mathrm{gr}$ en comparación a la población de hongos que siempre estuvo entre $10^{4}$ y $10^{5}$ ufc/gr. Estos resultados concuerdan con el comportamiento de poblaciones microbianas en suelo reportado por Alexander (1994). El estudio comparativo de las dos regiones, indica que la correspondiente a Puno muestra una mayor población de bacterias totales, lo que se puede deber entre otros factores al $\mathrm{pH}$ del suelo que es más alcalino, una altura menor y temperatura un poco mayor que la región de Huancavelica (Tabla 1). Esto demuestra que el $\mathrm{pH}$ podría ser determinante en el desarrollo de las poblaciones microbianas sobre todo por que su diferencia con la región de Huancavelica es considerable. Otro factor importante que puede influenciar las poblaciones microbianas es la cantidad de fósforo disponible. En Puno, el fósforo disponible en el suelo es mayor que en la región de Huancavelica; esto puede estar afectando también la población de bacterias totales en la rizósfera (Reyes \& Valery, 2007). En el caso de las poblaciones de hongos se sabe que éstas son más competitivas en suelos ácidos (Alexander, 1994), sin embargo, cuando se habla de rizósfera, los exudados producidos por las plantas pueden jugar un rol tan determinante como el tipo de suelo (Marschner et al., 2004; Reyes \& Valery, 2007). Por esta razón las poblaciones de hongos en la región de Puno a pesar de poseer $\mathrm{pH}$ más alcalinos que Huancavelica son más altas excepto en la localidad de Ichu y Challa (muestras 1 y 5 de la Tabla 5) que presentan menores poblaciones de hongos. Todo esto indica que la dinámica microbiana en la rizósfera puede variar considerablemente de la dinámica poblacional del suelo, y la presencia de microorganismos puede estar altamente influenciada por los exudados vegetales y por otras poblaciones propias de la rizósfera. Las poblaciones de Actinomicetos y Azotobacter spp. muestran valores menores en la región de Huancavelica y esto se puede deber también a la presencia de suelos con pH ácido lo que confirma el comportamiento de estos dos géneros que prefieren suelos con $\mathrm{pH}$ más alcalino (Hervé et al., 1994).

En cuanto a los tipos de fertilización que presenta el campo 2 en Huancavelica, se observa que de todos los tratamientos, el que contiene sólo fósforo tiene una mayor población de bacterias del género Azotobacter; este comportamiento ya ha sido observado por Pahuara \& Zúñiga (2001). Los niveles altos de fósforo pueden favorece la presencia de Azotobacter en el suelo y esto se puede deber a que el fósforo favorece el crecimiento de microorganismos debido a su rol estructural en membranas citoplasmáticas (fosfolípidos) en todos los seres vivos y por su participación en la acumulación y liberación de energía en el metabolismo celular (Madigan et al., 1997). En general las poblaciones de Azotobacter spp. en este campo tienden a estar favorecidas por la fertilización química (Tabla 4); por el contrario, las poblaciones de Bacillus spp. se ven afectadas y disminuyen en los tratamientos con fertilización química (Tabla 4). En cuanto a la presencia de ambas poblaciones microbianas descritas previamente, en el tratamiento control sus poblaciones fueron menores que las poblaciones encontradas por Oswald et al. (2007) en campos de la misma región y en la misma época de cultivo pero en variedad Queccorani, Yungay y Putis, lo que podría indicar, entre otros factores, la influencia de la variedad de papa sobre sus 
poblaciones. En cuanto a las poblaciones de Bacillus spp. se observa una población más alta en Puno; esto se puede deber a la preferencia de este género por el pH cerca al neutro, sin embargo, su presencia también es significativa en los suelos de Aymara, lo que indica que las bacterias de este género presentes en estos suelos están adaptadas y tienen más posibilidad de sobrevivir gracias a su capacidad de formar esporas (Claus \& Berkeley, 1986) lo que ayuda a su supervivencia. Los análisis de las poblaciones microbianas representativas de estas regiones, brindan importante información del comportamiento de los microorganismos en la rizósfera bajo diferentes condiciones, sin embargo, es importante mencionar que la dinámica de poblaciones en la rizósfera es un aspecto muy complejo y involucra numerosos factores que actuando en conjunto benefician el desarrollo de ciertas poblaciones microbianas. Al hablar de rizósfera también juegan un papel importante las características de las plantas y los exudados producidos. Estos factores hacen que se establezca una relación plantamicroorganismo compleja y dinámica en la zona de la rizósfera (Persello-Cartieaux et al., 2003; Zúñiga \& Gutiérrez-Correa, 1982). Las sustancias o exudados producidos por las raíces sirven como fuente energética y pueden llegar a inducir incluso cambios de $\mathrm{pH}$, disponibilidad de sustratos, nutrientes y factores de crecimiento microbiano en la rizósfera moldeando de esta manera su dinámica poblacional (Reyes \& Valery, 2007).

Un efecto también observado en este trabajo, es el de la variedad de cultivo en el campo 1 de Huancavelica, a pesar de presentar las mismas condiciones de suelo y manejo, el suelo rizosférico de la variedad Peruanita tiene mayor población de bacterias totales y hongos totales que el de la variedad Amarilla (Tabla 3), pero el de la Amarilla tiene mayores poblaciones de Azotobacter y Actinomicetos, por lo tanto en este caso, las variedades de papas pueden jugar un rol importante en las poblaciones de la rizósfera confirmando una vez más que los exudados influyen mucho en la dinámica de poblaciones de la rizósfera. El efecto de la variedad o del cultivar ya ha sido reportado por Grayer et al. (2004), esto es debido a que a pesar de ser especies del mismo género, pueden presentar diferencias fisiológicas que se traducen en la composición bioquímica de los exudados radiculares (Silva et al., 2003).

Por otro lado, los aislamientos realizados en este trabajo, nos dan un indicio de la diversidad de bacterias que se pueden encontrar, por esta razón la cantidad hallada de cada microorganismo se basa en las diferentes morfologías de colonias encontradas. Las colonias identificadas para le caso de Bacillus spp. fueron aquellas colonias blanquecinas con bordes irregulares y de apariencia seca (Wakita et al., 2001). En caso de Azotobacter las colonias que se presentan
Tabla 3. Poblaciones de Bacterias totales, Azotobacter spp., Actinomicetos y Hongos totales presentes en el campo 1 en la región de Huancavelica con la variedades Peruanita y Amarilla.

\begin{tabular}{|c|c|c|}
\hline \multirow{2}{*}{ Recuento } & \multicolumn{2}{|c|}{ Variedad de papa } \\
\hline & Peruanita & Amarilla \\
\hline Bacterias totales ufc/grs & $71.4 \times 10^{6}$ & $13.5 \times 10^{6}$ \\
\hline Bacillus spp. ufc/grs & $34.8 \times 10^{3}$ & $76 \times 10^{3}$ \\
\hline Azotobacter spp. NMP/grs & 40 & 70 \\
\hline Actinomicetos ufc/grs & $33 \times 10^{2}$ & $93 \times 10^{4}$ \\
\hline Hongos & $96 \times 10^{3}$ & $50 \times 10^{3}$ \\
\hline
\end{tabular}

ufc/grs: unidades formadoras de colonia por gramo de suelo rizosférico seco. NMP: Número más probable.

son transparentes, con bordes regulares y con la apariencia de una gota de agua (Zúñiga \& GutiérrezCorrea, 1982), por último el reconocimiento de colonias de Actinomicetos es relativamente sencillo, debido a su apariencia seca en forma de costra y por la presencia de esporas, otra característica es el olor que tienen debido a la producción de la sustancia geosmina (Gerber \& Lechevalier, 1965). Del total de 17 muestras procesadas se obtuvieron 63 aislamientos de Bacillus spp., 29 fueron aisladas de la región de Huancavelica lo que representa el $46 \%$ del total de aislamientos y 34 fueron aisladas de la región de Puno lo que representa el $54 \%$ del total de aislamientos (Tabla 6), por lo tanto la presencia de Bacillus spp. en la rizósfera del cultivo de papa en Puno y Huancavelica es significativa. Se han encontrado cantidades similares de aislamientos en las dos regiones lo que indica su presencia activa en la rizósfera de papa incluso en diferentes condiciones de suelo. Estudios realizados sobre las poblaciones microbianas en la rizósfera de diversos cultivos mencionan una presencia alta de microorganismos Gram negativos principalmente de los géneros Pseudomonas, Arthrobacter, Agrobacterium, Azotobacter, Mycobacterium etc. (Smit et al., 2001) sin embargo, estudios a nivel molecular demuestran una presencia bastante significativa del género Bacillus en la rizósfera de diferentes cultivos incluyendo papa (Smalla et al., 2001); Sturz (1995) también demostró una presencia significativa de Bacillus spp. en la rizósfera de la variedad de papa Kennebec, lo que nos confirma que este género se encuentra muy relacionado a la rizósfera de este cultivo. En cuanto a las características fisicoquímicas del suelo, se observó que inclusive en la región de Huancavelica donde el suelo es acido, hay presencia de una buena cantidad de aislamientos de Bacillus. Esto ya ha sido reportado anteriormente por Pal (1998) que encontró que la cepa de Bacillus PAS-2 es capaz de crecer a $\mathrm{pH}$ 4.8 Del grupo de Actinomicetos se encontraron un total de 37 
Tabla 4. Poblaciones de Bacterias totales, Azotobacter spp., Actinomicetos y Hongos totales presentes en el campo 2 en la región de Huancavelica con la variedad Peruanita.

\begin{tabular}{lcccccc}
\hline & \multicolumn{3}{c}{ Tratamientos } \\
\cline { 2 - 6 } & $\begin{array}{c}\text { Control } \\
\text { Peruanita }\end{array}$ & $\begin{array}{c}\text { Nitrato } \\
\text { Peruanita }\end{array}$ & $\begin{array}{c}\text { Cal+Nitrato } \\
\text { Peruanita }\end{array}$ & $\begin{array}{c}\text { Fosfato } \\
\text { Peruanita }\end{array}$ & $\begin{array}{c}\text { Guano +Nitrato } \\
\text { Peruanita }\end{array}$ & $\begin{array}{c}\text { Nitrato +Fosfato } \\
\text { Peruanita }\end{array}$ \\
\hline Bacterias totales ufc/grs & $11.9 \times 10^{6}$ & $73 \times 10^{6}$ & $17.9 \times 10^{6}$ & $11.6 \times 10^{6}$ & $23.5 \times 10^{6}$ & $11.0 \times 10^{6}$ \\
Bacillus spp. Ufc/grs & $14.8 \times 10^{4}$ & $87.6 \times 10^{3}$ & $56 \times 10^{3}$ & $76.9 \times 10^{3}$ & $83.7 \times 10^{3}$ & $40.8 \times 10^{3}$ \\
Azotobacter spp. NMP & 55.6 & 76.4 & 87.8 & 88 & 83.9 & 87.7 \\
Actinomicetos ufc/grs & $75 \times 10^{3}$ & $20 \times 10^{3}$ & $40 \times 10^{2}$ & $50 \times 10$ & $72 \times 10^{3}$ & $10 \times 10^{2}$ \\
Hongos ufc/grs & $98 \times 10^{3}$ & $64 \times 10^{3}$ & $54 \times 10^{3}$ & $74 \times 10^{3}$ & $39 \times 10^{3}$ & $75 \times 10^{3}$ \\
\hline
\end{tabular}

Ufc/grs: unidades formadoras de colonia por suelo rizosférico seco. NMP: Número más probable

Tabla 5. Poblaciones de Bacterias totales, Azotobacter spp., Actinomicetos y Hongos totales presentes en nueve localidades en la región de Puno con las variedades Imilla Negra y Ccompis.

\begin{tabular}{|c|c|c|c|c|c|c|c|c|c|}
\hline & \multicolumn{9}{|c|}{ Localidades Muestreadas } \\
\hline & $\begin{array}{c}\mathrm{L1} \\
\text { Ccompis }\end{array}$ & $\begin{array}{c}\mathrm{L} 2 \\
\text { Ccompis }\end{array}$ & $\begin{array}{c}\text { L3 } \\
\text { Ccompis }\end{array}$ & $\begin{array}{c}\text { L4 } \\
\text { Ccompis }\end{array}$ & $\begin{array}{c}\text { L5 } \\
\text { Ccompis }\end{array}$ & $\begin{array}{c}\text { L6 } \\
\text { Imilla } \\
\text { negra }\end{array}$ & $\begin{array}{c}\text { L7 } \\
\text { Ccompis }\end{array}$ & $\begin{array}{c}\text { L8 } \\
\text { Imilla } \\
\text { negra }\end{array}$ & $\begin{array}{c}\text { L9 } \\
\text { Imilla } \\
\text { negra }\end{array}$ \\
\hline $\begin{array}{l}\text { Bacterias totales } \\
\text { ufc/grs }\end{array}$ & 17. $9 \times 10^{8}$ & 54. $2 \times 10^{7}$ & $79.5 \times 10^{7}$ & $84 \times 10^{7}$ & $53 \times 10^{7}$ & $23 \times 10^{7}$ & $45 \times 10^{6}$ & $32.2 \times 10^{7}$ & $51.2 \times 10^{7}$ \\
\hline $\begin{array}{l}\text { Bacillus spp } \\
\text { Ufc/grs }\end{array}$ & $31.5 \times 10^{4}$ & $54.8 \times 10^{4}$ & $22.8 \times 10^{4}$ & $14.5 \times 10^{4}$ & $43.2 \times 10^{4}$ & $33 \times 10^{4}$ & $22.7 \times 10^{4}$ & $39 \times 10^{4}$ & $50.7 \times 10^{4}$ \\
\hline $\begin{array}{l}\text { Azotobacter spp } \\
\text { NMP }\end{array}$ & 85.3 & 89.5 & 87.3 & 99.6 & 95.3 & 91.2 & 88.2 & 75.2 & 90.2 \\
\hline $\begin{array}{l}\text { Actinomicetos } \\
\text { ufc/grs }\end{array}$ & $40 \times 10^{3}$ & $25 \times 10^{3}$ & $33 \times 10^{3}$ & $31 \times 10^{3}$ & $28 \times 10^{3}$ & $45 \times 10^{3}$ & $15.2 \times 10^{3}$ & $42.1 \times 10^{3}$ & $17.6 \times 10^{3}$ \\
\hline $\begin{array}{l}\text { Hongos } \\
\text { ufc/grs }\end{array}$ & $88 \times 10^{3}$ & $16 \times 10^{4}$ & $22 \times 10^{4}$ & $40 \times 10^{3}$ & $80 \times 10^{3}$ & $11 \times 10^{4}$ & $17.5 \times 10^{4}$ & $25 \times 10^{4}$ & $31 \times 10^{4}$ \\
\hline
\end{tabular}

Ufc/grs: unidades formadoras de colonia por suelo rizoférico seco. NMP: Número más probable

diferentes aislamientos 32 provenían de Huancavelica y 5 de Puno, la diversidad de colonias encontrada en la región de Huancavelica fue mucho mayor que la encontrada en Puno. Inclusive sabiendo que los Actinomicetos prefieren valores de pHs cercanos al neutro, la diversidad de microorganismos en la región de Huancavelica nos indica que varias diferentes especies están adaptadas a estas condiciones y sobre todo mantienen una relación con la raíces a nivel de rizósfera que puede equilibrar las condiciones fisicoquímicas presentadas en este suelo; si bien las poblaciones de Actinomicetos en su mayoría son más abundantes en la región de Puno, la mayor diversidad de colonias se da en la región de Huancavelica aún con poblaciones bajas, esto se puede deber a que las poblaciones altas de Puno se deben a la abundancia de solo unos cuantos tipos de colonias predominantes en la rizósfera, asimismo, Harris (1992) menciona que la presencia de un mayor porcentaje de materia orgánica, como el observado en Huancavelica, puede favorecer el desarrollo de una mayor diversidad de microorganismos.

En cuanto al género Azotobacter spp. se observa el mismo comportamiento que en los Actinomicetos, se encontró un mayor numero de aislamientos en Huancavelica (Tabla 6), en este caso las poblaciones de Puno y Huancavelica son similares, sin embargo, la mayor cantidad de aislamientos se debe a una mayor diversidad de colonias encontradas en Huancavelica, esto se puede deber a que las poblaciones de Azotobacter spp. además se ven favorecidas por la presencia de una mayor cantidad de materia orgánica en el suelo (González et al., 1999).

Los resultados encontrados nos demuestran que no siempre una mayor población de microorganismos equivale a una mayor diversidad de microorganismos. Existen casos donde habrá la predominancia de una especie sobre la otra, lo que ocurre principalmente por la competencia que existe entre géneros y especies por el predominio en un ambiente como la rizósfera.

Al evaluar poblaciones también hay que tomar en cuenta la dinámica e interacciones entre los diferentes géneros de bacteria, en el caso de los Actinomicetos se ha comprobado que pueden tener un efecto antagónico con las bacterias del género Azotobacter spp. (González et al., 1999) asimismo se menciona la acción competitiva entre estos dos grupos por un

Tabla 6. Aislamientos encontrados en las dos regiones de muestreo de Puno y Huancavelica.

\begin{tabular}{lccc}
\hline $\begin{array}{c}\text { Género de } \\
\text { bacteria }\end{array}$ & $\begin{array}{c}\text { Número total } \\
\text { de aislamientos }\end{array}$ & $\begin{array}{c}\text { Aislamientos } \\
\text { Huancavelica }\end{array}$ & $\begin{array}{c}\text { Aislamientos } \\
\text { Puno }\end{array}$ \\
\hline Azotobacter spp. & 50 & $37(74 \%)^{*}$ & $13(26 \%)^{*}$ \\
Actinomicetos & 37 & $32(87 \%)^{*}$ & $5(13 \%)^{*}$ \\
Bacillus spp. & 63 & $29(46 \%)^{*}$ & $34(54 \%)^{*}$ \\
\hline
\end{tabular}

* Porcentaje de aislamientos correspondientes a cada género encontrados en cada región. 
sustrato común, sin embargo, en la rizósfera observamos la presencia de estos dos géneros, aunque en algunos casos hay más abundancia de Actinomicetos.

\section{Agradecimientos:}

El trabajo ha sido financiado por el proyecto Procyt-Concytec 163-2006: “Control de Fitopatógenos del cultivo de Papa por bacterias Antagónicas aisladas del mismo cultivo", Centro Internacional de la Papa y la Fundación para el Desarrollo Agrario, Sub- Cuenta 111 Biología/UNALM.

\section{Literatura citada}

Alexander M. 1994. Introducción a la Microbiología de Suelos. Editor S. A. México.

American Public Health Association (APHA). 1975. Standard Methods for examination of water and waste water.14 ed. Washington DC, EEUU.

American Public Health Association (APHA). 1998. Standard Methods for examination of water and waste water. 20 ed. Washington DC, EEUU.

Ariena H.C., Van Bruggen A., Semenov M., Van Diepeningen A.D., De Vos O.J. \& Blok W.J. 2006. Relation between soil health, wave-like fluctuations in microbial populations, and soil-borne plant disease management. European Journal of Plant Pathology. 115: 105-122.

Claus D. \& Berkeley R.C.W. 1986. Genus Bacillus. En Bergey's Manual of Systematic Bacteriology (Eds. P. H. Sneath, N. Mair, M. E. Sharpe and J.G. Holt), Baltimore, Williams and Wilkins, 9 na. Edición. Vol. 2, pp. 1105-1139.

Foldes T, Banhegyi I., Herpai Z., Varga L., Szigeti J. 2000. Isolation of Bacillus strains from the rhizosphere of cereals and in vitro screening for antagonism against phytopathogenic, food-borne pathogenic and spoilage microorganisms. Journal of Applied Microbiology. 89: 840-846.

Foster R.C. 1998. Microenvironments of soil microorganisms. Biology and Fertility of Soils. 6: 189203.

Gerber N.N. \& Lechevalier H.A.1965. Geosmin, an EarthySmelling Substance Isolated from Actinomycetes . Applied Microbiology. 13: 935-938.

Glick B.R. 1995. The enhancement of plant growth by freeliving bacteria. Canadian Journal of Microbiology 41: 109-117.

González C.H., Rodríguez L., Arjona C., Puertas A. \& Fonseca M. 1999. Efecto de la Aplicación de Trichoderma harzianum R. Sobre la Composición Cuantitativa De Bacterias, Hongos y Actinomicetos de la Rizósfera de Solanaceas y su Influencia en el Crecimiento Vegetativo. Investigación Agraria, Producción y Protección Vegetales. 14: 297-306.

Grayer R., Vieira R., Price A., Kite G., Simon J. \& Paton A. 2004.Characterization of cultivars within species of Ocimun by exúdate flavonoid profiles. Biochemical Systematics and Ecology. 32: 901-913.

Harris P.J. 1992. Ecología de la población del suelo En: Condiciones del suelo y desarrollo de las plantas. Comp. A. Wild. Madrid: Mundi-Prensa, España.
Hervé D., Genin D. \& Rivière G. 1994. Dinámicas del descanso de la tierra en los Andes. Eds. IBTA ORSTOM. La Paz, Bolivia.

Hiltner L. 1904. Über neurer erfahrunger und problem auf dem gebeit der bodenbakteriologie und unter besonderer berucksinchtingung der grundungung und brache. Arbeiten Deutscher Landwirtschafts Gesellschaft. 98: 59-78.

Killian M., Steiner U., Krebs B., Junge H., Schmiedeknecht G. \& Hain R. 2001. FZB24 Bacillus subtilis Mode of Action of a Microbial Agent Enhancing Plant Vitality. Pflanzenschut - Nachrichten Bayer. 1: 72-93.

Krupa S.W. \& Dommergues Y.K. 1981. Ecology of root pathogens; 2da.ed. Elsevier scientific publishing company. EEUU.

Loynachan T. E. 2001. Soil Microbiol Ecology Laboratory Manual. Iowa State University (EEUU). pp. 76.

Lynch J.M. 1990. The rhizosphere. Willey-Interscience, Chichester, Inglaterra.

Madigan M., Martinko J. \& Parker J. 1997. Brock Biología de los Microorganismos. Octava Edición. Prentice Hall.EEUU.

Marschner P., Crowley D. \& Hong Yang C. 2004. Development of specific rhizosphere bacterial communities in relation to plant species, nutrition and soil type. Plant and Soil. 261: 199-208.

Merck 1994. Manual de Medios de Cultivo. E. Merck, Darmstandt, Alemania.

Ministerio de Agricultura y Alimentación. Dirección general de Investigación. 1978. Evaluación de la fertilidad de los suelos en el Perú. Perú.

MINAG (Ministerio de Agricultura). 2003. OGPA-DGPA Plan Estratégico de la Cadena de La Papa. Perú.

Olalde P.V. \& Aguilera L.L. 1998. Microorganismos y Biodiversidad. Terra. 16: 289-292.

Oswald A., Calvo P., Sanchez J. \& Zúñiga D. 2007. Using Plant Growth Promoting Rhizobacteria to improve potato production and plant health. 401-107. In: mineral versus organic fertilization conflict or synergism? Proceedings 16th International Symposium of the International Scientific Center of Fertilizers (CIEC),1619 September, Ghent, Belgium.

Pahuara D. \& Zúñiga D. 2001. Efecto del fósforo sobre la población microbiana en suelos con pasturas en la zona altoandina de Junín. Ecología Aplicada. 1: 57-64.

Pal S.S. 1998. Interactions o fan acid tolerant strain of phosphate solubilizing bacteria with a few acid tolerante crops. Plant and Soil. 198: 169-177.

Paul E. \& Clark A. 1989. Soil microbiology and biochemistry. Academic Press, San Diego, California, EEUU.

Persello-Cartieaux F., Nussaume L. \& Robaglia C. 2003. Tales from the underground: molecular PlantRhizobacteria interactions. Plant, Cell and Environment. 26: 189-199.

Primavesi A. 1984. Manejo Ecológico del Suelo. Editorial El Ateneo. Buenos Aires, Argentina.

Reyes I. \& Valery A. 2007. Efecto de la fertilidad del suelo sobre la microbiota y la promoción del crecimiento (Zea mays L.) con Azotobacter spp. Bioagro. 19: 117-126.

Silva K., Salles F., Seldini L. \& Elsas J. 2003. Application of a novel Paenibacillus-specific PCR-DGGE method and sequence analysis to asses the diversity of 
Paenibacillus spp. in the maize rhizosphere. Journal of Microbiological Methods. 54: 213-231.

Smalla K., Wieland G., Buchner A., Zock A., Parzy J., Kaiser N., Roskot H., Heuer H. \& Berg G. 2001. Bulk and Rhizosphere Soil Bacterial Communities Studied by Denaturing Gradient Gel Electrophoresis: PlantDependent Enrichment and Seasonal Shifts Revealed. Applied and Environmental Microbiology. 67: 47424751.

Smit E., Leeflang P., Gommans S., van den Broek J., van Mil S. \& Wernars K. 2001 Diversity and seasonal fluctuations of the dominant members of the bacterial soil community in a wheat field as determined by cultivation and molecular methods. Applied Environmental Microbiology. 67: 2284-2291.

Sturz A. 1995. The role of endophytic bacteria during seed piece decay and potato tuberization. Plant and Soil. 175: 257-263.
Tate R.L. 1995. Soil microbiology. John Wiley \& sons, New York, EEUU.

Wakita J., Shimada H., Itoh H., Matsuyama T. \& Matsushita M. 2001. Periodic Colony Formation by Bacterial Species Bacillus subtilis. Journal of the Physical Society of Japan. 70: 911-919.

Zapater J. 1975. Evaluación en el maíz del coeficiente rizósfera - suelo (R/S) referidos a bacterias libres fijadoras de N2. Anales Científicos de la U.N.A. 13: 4557.

Zúñiga D. \& Gutiérrez-Correa M. 1982. Dinámica poblacional de diazótrofos libres fijadores de nitrógeno en la rizósfera de Sicyos baderoa. Zonas Áridas. 2: 7986.

${ }^{1}$ Laboratorio de Ecología Microbiana y Biotecnología Marino Tabusso, Dpto. de Biología, Universidad Nacional Agraria La Molina, Av. La Molina s/n La Molina. Lima - Perú. p.calvo@cgiar.org

${ }^{2}$ Laboratorio de Ecología Microbiana y Biotecnología Marino Tabusso, Dpto. de Biología, Universidad Nacional Agraria La Molina, Av. La Molina s/n La Molina. Lima - Perú.

${ }^{3}$ Laboratorio de Ecología Microbiana y Biotecnología Marino Tabusso, Dpto. de Biología, Universidad Nacional Agraria La Molina, Av. La Molina s/n La Molina. Lima - Perú. Email. dzuniga@lamolina.edu.pe, web:

www.lamolina.edu.pe/lmt 